\title{
Electrical and magnetic properties of ion-exchangeable layered ruthenates
}

\author{
Wataru Sugimoto, ${ }^{*}$ Masashi Omoto, Katsunori Yokoshima, Yasushi Murakami, \\ and Yoshio Takasu
}

Department of Fine Materials Engineering, Faculty of Textile Science and Technology, Shinshu University, 3-15-1 Tokida, Ueda 386-8567, JAPAN

* corresponding author. Fax: +81-268-22-9048

E-mail address: wsugi@shinshu-u.ac.jp (W.Sugimoto) 


\section{Abstract}

An ion-exchangeable ruthenate with a layered structure, $\mathrm{K}_{0.2} \mathrm{RuO}_{2.1}$, was prepared by solid-state reactions. The interlayer cation was exchanged with $\mathrm{H}^{+}, \mathrm{C}_{2} \mathrm{H}_{5} \mathrm{NH}_{3}{ }^{+}$, and $\left(\left(\mathrm{C}_{4} \mathrm{H}_{9}\right)_{4} \mathrm{~N}^{+}\right)$through proton-exchange, ion-exchange, and guest-exchange reactions. The electrical and magnetic properties of the products were characterized by d.c. resistivity and susceptibility measurements. Layered $\mathrm{K}_{0.2} \mathrm{RuO}_{2.1}$ exhibited metallic conduction between 300-13 K. The products exhibited similar magnetic behavior despite the differences in the type of interlayer cation, suggesting that the ruthenate sheet in the protonated form and the intercalation compounds possesses metallic nature.

Keywords: Layered oxide; Ruthenate; Ion-exchange; Intercalation; Electrical properties; Magnetic properties 


\section{Introduction}

The capability of ion-exchangeable layered oxides to accommodate various organic cations and molecules in the two-dimensional interlayer space makes such material an interesting target for ordered inorganic-organic hybrid materials with mixed characteristic of the inorganic oxide layer and the organic interlayer [1-4]. In general, the inorganic layer is composed of an insulating or poorly conducting oxide layer such as titanates, niobates, and tantalates [1-4]. Some examples of carrier doping into ion-exchangeable layered transition metal oxides have been reported, e.g. Mo and W-based bronze, layered vanadium oxides (see refs. [5-7] for comprehensive reviews), and more recently, $\mathrm{Na}_{x} \mathrm{CoO}_{2}$ [8]. Such materials are conductive when the transition metal is in a mixed valence state, i.e. in the doped state, thus the conductivity is sensitive to the amount of interlayer cation.

Ruthenium dioxide, $\mathrm{RuO}_{2}$, is a unique oxide that has metallic conduction and can be easily handled under ambient conditions $[9,10]$. In addition, it is photochemically and electrochemically active and stable in acidic and alkaline electrolytes $[9,10]$. Due to such characteristics, $\mathrm{RuO}_{2}$ has been widely used as catalysts, electrocatalysts, bottom electrodes, and electrode materials for electrochemical capacitors (also known as supercapacitors, ultracapacitors, or pseudocapacitors) [10-16].

Ruthenates with layered structures, such as $\mathrm{Li}_{x} \mathrm{RuO}_{2}$ [17-19] and $\mathrm{Sr}_{2} \mathrm{RuO}_{4}$ [20] exhibit metallic behavior. However, these compounds do not have ion-exchange capabilities; thus chemical modification of these layered ruthenates is intricate. Quite recently, two new layered ruthenates have been synthesized, $\mathrm{K}_{0.2} \mathrm{RuO}_{2.1} \cdot n \mathrm{H}_{2} \mathrm{O}[21,22]$ 
and $\mathrm{Na}_{x} \mathrm{RuO}_{2} \cdot n \mathrm{H}_{2} \mathrm{O}$ [23]. The interlayer potassium ions in $\mathrm{K}_{0.2} \mathrm{RuO}_{2.1} \cdot n \mathrm{H}_{2} \mathrm{O}$ could be exchanged to protons to give the protonic form, $\mathrm{H}_{0.2} \mathrm{RuO}_{2.1} \cdot n \mathrm{H}_{2} \mathrm{O}$, by a simple proton-exchange reaction in acid [22]. Furthermore, organic cations such as ethylammonium and tetrabutylammonium could be intercalated into the interlayer space. In addition, delamination (exfoliation) into ruthenic acid nanosheets could be accomplished by dispersing the tetrabutylammonium-ruthenic acid intercalation compound in solvents [22]. Such material could be used as electrode materials for electrochemical capacitors, due to the high electrochemically active surface area and presumable high conductivity [22,24]. Here we report the electrical and magnetic properties of layered $\mathrm{K}_{0.2} \mathrm{RuO}_{2.1}$ and the magnetic properties of the derivatives with various interlayer cations, namely, $\quad \mathrm{H}_{0.2} \mathrm{RuO}_{2.1}, \quad\left(\mathrm{C}_{2} \mathrm{H}_{5} \mathrm{NH}_{3}\right)_{0.2} \mathrm{RuO}_{2.1}$ and $\left.\left(\mathrm{C}_{4} \mathrm{H}_{9}\right)_{4} \mathrm{~N}\right)_{0.2} \mathrm{RuO}_{2.1}$.

\section{Experimental}

Layered $\mathrm{K}_{0.2} \mathrm{RuO}_{2.1}$ was obtained by a solid-state reaction of a pelletized mixture of $\mathrm{K}_{2} \mathrm{CO}_{3}$ and $\mathrm{RuO}_{2}$ (5:4 molar ratio) under Ar flow at $850^{\circ} \mathrm{C}$ for $12 \mathrm{~h}$. The product was ground into fine powder and then washed with copious amounts of water and dried at $120^{\circ} \mathrm{C}$. Layered $\mathrm{K}_{0.2} \mathrm{RuO}_{2.1}$ was converted into the protonic form, layered $\mathrm{H}_{0.2} \mathrm{RuO}_{2.1} \cdot n \mathrm{H}_{2} \mathrm{O}$, by acid treatment with $0.5 \mathrm{M} \mathrm{H}_{2} \mathrm{SO}_{4}$ at $60^{\circ} \mathrm{C}$ for $48 \mathrm{~h}$, followed by washing with copious amounts of water. $\mathrm{H}_{0.2} \mathrm{RuO}_{2.1} \cdot n \mathrm{H}_{2} \mathrm{O}$ was dried at $120^{\circ} \mathrm{C}$ to remove interlayer water before characterization of the structure, electric 
and magnetic properties. The cation ratio of the product after the acid treatment was $\mathrm{K}: \mathrm{Ru}=<0.05: 1$, based on ICP, EDAX and XPS analysis [22]. The ethylammonium-ruthenic acid intercalation compound, $\left(\mathrm{C}_{2} \mathrm{H}_{5} \mathrm{NH}_{3}\right)_{0.2} \mathrm{RuO}_{2.1}$, was prepared by reaction of layered $\mathrm{H}_{0.2} \mathrm{RuO}_{2.1} \cdot n \mathrm{H}_{2} \mathrm{O}$ with a $50 \%$ ethylamine aqueous solution. The solid product was centrifugally collected $(15,000 \mathrm{rpm})$, washed with acetone and vacuum dried. The tetrabutylammonium-ruthenic acid intercalation compound, $\left.\left(\mathrm{C}_{4} \mathrm{H}_{9}\right)_{4} \mathrm{~N}\right)_{0.2} \mathrm{RuO}_{2.1}$, was prepared by reaction of the ethylammonium-ruthenic acid intercalation compound with a $10 \%$ tetrabutylammonium hydroxide aqueous solution. The solid product was centrifugally collected $(15,000 \mathrm{rpm})$. The X-ray diffraction patterns of the products were in agreement with our previous study [22]. The basal spacings measured from the lowest angle reflections for $\mathrm{K}_{0.2} \mathrm{RuO}_{2.1}, \mathrm{H}_{0.2} \mathrm{RuO}_{2.1}$, $\left(\mathrm{C}_{2} \mathrm{H}_{5} \mathrm{NH}_{3}\right)_{0.2} \mathrm{RuO}_{2.1}, \quad\left(\left(\mathrm{C}_{4} \mathrm{H}_{9}\right)_{4} \mathrm{~N}\right)_{0.2} \mathrm{RuO}_{2.1}$, were $0.729, \quad 0.456, \quad 0.815,1.690 \mathrm{~nm}$, respectively. The difference in the basal spacing is in reasonable agreement with the size of the interlayer cations.

Resistivity data were collected from 280 to $13 \mathrm{~K}$ using a standard dc four-probe method with Ag paste contacts. $\quad$ Polycrystalline powders of $\mathrm{K}_{0.2} \mathrm{RuO}_{2.1}$ and rutile-type $\mathrm{RuO}_{2}$ were pressed into pellets and sintered again at $850^{\circ} \mathrm{C}$ for $12 \mathrm{~h}$ under Ar flow for the resistivity measurements. Rutile-type $\mathrm{RuO}_{2}$ was obtained by calcination of commercial $\mathrm{RuO}_{2} \cdot n \mathrm{H}_{2} \mathrm{O}$ (Johnson Matthey) at $850^{\circ} \mathrm{C}$ for $12 \mathrm{~h}$ under Ar flow. Since layered $\mathrm{H}_{0.2} \mathrm{RuO}_{2.1}$ undergoes interlayer dehydration and condensation at elevated 
temperatures, the resistivity data was collected using a non-sintered pellet of $\mathrm{H}_{0.2} \mathrm{RuO}_{2.1}$ dried at $120^{\circ} \mathrm{C}$. Resistivity measurements for a non-sintered pellet of amorphous $\mathrm{RuO}_{2} \cdot n \mathrm{H}_{2} \mathrm{O}(n \sim 0.8)$ dried at $150^{\circ} \mathrm{C}$ were also conducted, since this composition has been reported as to be the most suitable for electrochemical capacitors $[15,16]$. Magnetic susceptibility of powder samples was measured in a magnetic field of $1 \mathrm{~T}$ from 300 to $5 \mathrm{~K}$ using a superconducting quantum interference device (SQUID) magnetometer (MPMS-7, Quantum Design) at Waseda University Material Characterization Central Laboratory. All of the analysis was conducted on anhydrous materials except for $\mathrm{RuO}_{2} \cdot n \mathrm{H}_{2} \mathrm{O}$.

\section{Results and discussion}

The normalized resistivity of layered $\mathrm{K}_{0.2} \mathrm{RuO}_{2.1}$ is compared with rutile-type $\mathrm{RuO}_{2}$ in Fig. 1. The room-temperature resistivity of layered $\mathrm{K}_{0.2} \mathrm{RuO}_{2.1}$ was $2 \mathrm{~m} \Omega \mathrm{cm}$, which is comparable to that of rutile-type $\mathrm{RuO}_{2}(0.5 \mathrm{~m} \Omega \mathrm{cm})$. The temperature dependency of the resistivity for layered $\mathrm{K}_{0.2} \mathrm{RuO}_{2.1}$ slightly increased with increasing temperature and exhibited a similar tendency to that of rutile-type $\mathrm{RuO}_{2}$. The low room-temperature resistivity and the temperature dependency show that the layered $\mathrm{K}_{0.2} \mathrm{RuO}_{2.1}$ exhibits metallic conduction, equivalent to the rutile-type $\mathrm{RuO}_{2}$.

Figure 2 shows the resistivity behavior of non-sintered pellets of layered $\mathrm{H}_{0.2} \mathrm{RuO}_{2.1}$ and amorphous $\mathrm{RuO}_{2} \cdot n \mathrm{H}_{2} \mathrm{O}$. The resistivity behavior of layered $\mathrm{H}_{0.2} \mathrm{RuO}_{2.1}$ is comparable with amorphous $\mathrm{RuO}_{2} \cdot n \mathrm{H}_{2} \mathrm{O}$, with the resistivity slightly 
decreasing with increasing temperature. The room-temperature resistivity of layered $\mathrm{H}_{0.2} \mathrm{RuO}_{2.1}$ and amorphous $\mathrm{RuO}_{2} \cdot n \mathrm{H}_{2} \mathrm{O}$ was 21 and $1 \mathrm{~m} \Omega \mathrm{cm}$, respectively. Although the temperature dependency of the resistivity of layered $\mathrm{H}_{0.2} \mathrm{RuO}_{2.1}$ and amorphous $\mathrm{RuO}_{2} \cdot n \mathrm{H}_{2} \mathrm{O}$ is not typical of metallic behavior, the temperature dependency is very weak, which suggests that the conduction mechanism probably does not involve a thermally activated process. The non-sintered state should lead to a relatively high inter-particle resistance. The low room-temperature resistivity in the order of $\mathrm{m} \Omega \mathrm{cm}$ and weak temperature dependency despite the non-sintered state of layered $\mathrm{H}_{0.2} \mathrm{RuO}_{2.1}$ and amorphous $\mathrm{RuO}_{2} \cdot n \mathrm{H}_{2} \mathrm{O}$ implies that these materials are highly electro-conductive.

In order to gain further insight into the properties of the layered ruthenates, magnetic susceptibility measurements were conducted on powder samples. The magnetic susceptibility $\chi$ of $\mathrm{M}_{0.2} \mathrm{RuO}_{2.1}\left(\mathrm{M}=\mathrm{K}^{+}, \mathrm{H}^{+}, \mathrm{C}_{2} \mathrm{H}_{5} \mathrm{NH}_{3}{ }^{+},\left(\mathrm{C}_{4} \mathrm{H}_{9}\right)_{4} \mathrm{~N}^{+}\right)$is shown as a function of the temperature in Fig. 3. The magnetic susceptibility $\chi$ is weakly temperature dependent for all the samples between 150 and $300 \mathrm{~K}$. The small magnetic susceptibility of $\sim 100 \times 10^{-6} \mathrm{emu} \mathrm{mol}^{-1}$ in this temperature region is characteristic of Pauli paramagnetism. In the case of $\mathrm{K}_{0.2} \mathrm{RuO}_{2.1}$, a minimum in the magnetic susceptibility $\chi$ was observed at $120 \mathrm{~K}$, characteristic of antiferromagnetic interactions in two-dimensional systems [25-27]. The temperature dependency of the magnetic susceptibility of $\mathrm{M}_{0.2} \mathrm{RuO}_{2.1}\left(\mathrm{M}=\mathrm{K}^{+}, \mathrm{H}^{+}, \mathrm{C}_{2} \mathrm{H}_{5} \mathrm{NH}_{3}{ }^{+},\left(\mathrm{C}_{4} \mathrm{H}_{9}\right)_{4} \mathrm{~N}^{+}\right)$is similar to that of $\mathrm{NaRuO}_{2}$ and $\mathrm{Na}_{x} \mathrm{RuO}_{2} \cdot n \mathrm{H}_{2} \mathrm{O}$ [23]. 
Figure 4 shows the reciprocal of the susceptibility normalized to the susceptibility at $300 \mathrm{~K}\left(\chi_{(300)} / \chi\right)$ as a function of temperature. The temperature dependency of the magnetic susceptibility for layered $\mathrm{H}_{0.2} \mathrm{RuO}_{2.1}$ is comparable to that of layered $\mathrm{K}_{0.2} \mathrm{RuO}_{2.1}$, except for the antiferromagnetic transition near $120 \mathrm{~K}$. The similarity in the magnetic behavior of $\mathrm{M}_{0.2} \mathrm{RuO}_{2.1}\left(\mathrm{M}=\mathrm{H}^{+}, \mathrm{C}_{2} \mathrm{H}_{5} \mathrm{NH}_{3}{ }^{+},\left(\mathrm{C}_{4} \mathrm{H}_{9}\right)_{4} \mathrm{~N}^{+}\right)$with metallic $\mathrm{K}_{0.2} \mathrm{RuO}_{2.1}$ suggests that the metallic characteristic of the ruthenate sheets is preserved regardless of the type of interlayer cation (organic or inorganic) and the different basal spacing. The apparent non-metallic behavior of layered $\mathrm{H}_{0.2} \mathrm{RuO}_{2.1}$ observed by the resistivity measurements (Fig. 2) may be due to inter-particle resistance, rather than an intrinsic characteristic of the differences in the interlayer cation. Hence, under the present experimental conditions, the electric and magnetic properties of the ion-exchangeable layered ruthenate seems to be dominated by the ruthenate sheets and the magnetic interaction between the sheets seems to be small. To the best of our knowledge, the layered ruthenate $\mathrm{M}_{0.2} \mathrm{RuO}_{2.1}$ is the first example of a family of highly conducting, chemically and electrochemically stable layered oxide that can easily be chemically modified through conventional intercalation chemistry. Figure 4

\section{Conclusions}

A series of layered ruthenates, $\mathrm{M}_{0.2} \mathrm{RuO}_{2.1}\left(\mathrm{M}=\mathrm{K}^{+}, \mathrm{H}^{+}, \mathrm{C}_{2} \mathrm{H}_{5} \mathrm{NH}_{3}^{+},\left(\mathrm{C}_{4} \mathrm{H}_{9}\right)_{4} \mathrm{~N}^{+}\right)$, was prepared by a solid-state reaction, an ion-exchange reaction, and a guest-exchange reaction. The resistivity data for sintered polycrystalline $\mathrm{K}_{0.2} \mathrm{RuO}_{2.1}$ revealed metallic 
conduction between 300-13 K. The magnetic susceptibility data of powder samples revealed that $\mathrm{M}_{0.2} \mathrm{RuO}_{2.1}\left(\mathrm{M}=\mathrm{K}^{+}, \mathrm{H}^{+}, \mathrm{C}_{2} \mathrm{H}_{5} \mathrm{NH}_{3}{ }^{+},\left(\mathrm{C}_{4} \mathrm{H}_{9}\right)_{4} \mathrm{~N}^{+}\right)$shows similar behavior, despite the differences in the interlayer cation. The results suggest that the ruthenate sheets in the ion-exchangeable layered ruthenates possess metallic behavior, making it the first example of a highly conducting, chemically and electrochemically stable layered oxide that can be easily chemically modified through conventional intercalation chemistry.

\section{ACKNOWLEDGEMENTS}

The authors gratefully thank Prof. Yoshiyuki Sugahara (Department of Applied Chemistry, Waseda University) and Dr. Toshimichi Shibue (MCCL, Waseda University) for the magnetic susceptibility measurements. This work was supported in part by an Industrial Technology Research Grant Program from the New Energy and Industrial Technology Development Organization (NEDO) and a MEXT 21st Century COE Program of Japan.

\section{REFERENCES}

[1] M.S. Whittingham, A.J. Jacobson, Intercalation Chemistry, Academic Press, New York, 1982.

[2] A.J. Jacobson, in: A.K. Cheetham, P. Day (Eds.), Solid State Chemistry: Compounds, Clarendon Press, Oxford, 1992, p. 182.

[3] D. O’Hare, in: D.W. Bruce, D. O’Hare (Eds.), Inorganic Materials, 2nd ed., John 
Wiley \& Sons, Chichester, 1996, p. 171.

[4] C.N.R. Rao, B. Raveau, Transition Metal Oxides, VCH Publishers, New York, 1995.

[5] M. Greenblatt, Chem. Rev. 88 (1988) 31-53.

[6] N.S.P. Bhuvanesh, J. Gopalkrishnan, J. Mater. Chem. 7 (1997) 2297-2306.

[7] R. Schöllhorn, Angew. Chem. Int. Ed. 19 (1980) 983-1003.

[8] K. Takada, H. Sakurai, E. Takayama-Muromach, F. Izumi, R.A. Dilanian, T. Sasaki, Nature 422 (2003) 53-55.

[9] S. Trasatti, in: S. Trasatti (Ed.), Electrodes of Conducting Metal Oxides, Elsevier, Amsterdam, Netherland, 1980, p. 301.

[10] J.B. Goodenough, Prog. Solid State Chem. 5 (1972) 145-399.

[11] S. Trasatti, Electrochim. Acta 36 (1991) 225-241.

[12] H. Over, Y. D. Kim, A. P. Seitsonen, S. Wendt, Lundgren, M. Schmid, P. Varga, A. Morgante, G. Ertl, Science 287 (2000) 1474-1476.

[13] L. Zang, H. Kisch, Angew. Chem. Int. Ed. 39 (2000) 3921-3922.

[14] B. Conway, in Electrochemical supercapacitors, Kluwer Academic/Plenum Publishers, New York, 1999.

[15] J. P. Zheng, T.R. Jow, J. Electrochem. Soc. 142 (1995) L6-L7.

[16] J. P. Zheng, P. J. Cygan, T. R. Jow, J. Electrochem. Soc. 142 (1995) 2699-2703.

[17] A.C.W.P. James, J.B. Goodenough, J. Solid State Chem. 74 (1988) 287-294.

[18] H. Kobayashi, R. Kanno, Y, Kawamoto, M. Tabuchi, O. Nakamura, M. Takano, Solid State Ionics 82 (1995) 25-31. 
[19] H. Kobayashi, R. Kanno, Y, Kawamoto, M. Tabuchi, O. Nakamura, Solid State Ionics 86-88 (1996) 859-863.

[20] Y. Maeno, H. Hashimoto, K. Yoshida, S. Nishizaki, T. Fujita, J.G. Bednorz, F. Lichtenberg, Nature 372 (1994) 532-534.

[21] Y. Takasu, Y. Murakami, Electrochim. Acta 45 (2000) 4135-4141.

[22] W. Sugimoto, H. Iwata, Y. Yasunaga, Y. Murakami, Y. Takasu, Angew. Chem. Int. Ed. 42 (2003) 4092-4096.

[23] M. Shikano, C. Delmas, J. Darriet, Inorg. Chem. 43 (2004) 1214-1216.

[24] W. Sugimoto, H. Iwata, Y. Murakami, Y. Takasu, J. Electrochem. Soc. 151 (2004) A1181-A1187.

[25] R.J. Cava, H.W. Zandbergen, J.J. Krajewski, W.F. Peck, Jr., B. Battlogg, S. Carter, R.M. Fleming, O. Zhou, L.W. Rupp, Jr., J. Solid State Chem. 116 (1995) 141-145.

[26] C. Dussarrat, F. Grasset, R. Bontchev, J. Alloys Compd. 233 (1996) 15-22.

[27] G. Cao, C.S. Alexander, S. McCall, J.E. Crow, R.P. Guertin, Mater. Sci. Eng. B63 (1999) 76-82. 


\section{LIST OF FIGURE CAPTIONS}

Figure 1 . The normalized resistivity as a function of the temperature for sintered pellets of (a) layered $\mathrm{K}_{0.2} \mathrm{RuO}_{2.1}$ and (b) rutile-type $\mathrm{RuO}_{2}$.

Figure 2. The normalized resistivity as a function of the temperature for non-sintered pellets of (a) layered $\mathrm{H}_{0.2} \mathrm{RuO}_{2.1}$ and (b) $\mathrm{RuO}_{2} \cdot n \mathrm{H}_{2} \mathrm{O}$.

Figure 3. The magnetic susceptibility for layered (a) $\mathrm{K}_{0.2} \mathrm{RuO}_{2.1}$, (b) $\mathrm{H}_{0.2} \mathrm{RuO}_{2.1}$, (c) $\left(\mathrm{C}_{2} \mathrm{H}_{5} \mathrm{NH}_{3}\right)_{0.2} \mathrm{RuO}_{2.1}$, and (d) $\left(\left(\mathrm{C}_{4} \mathrm{H}_{9}\right)_{4} \mathrm{~N}\right)_{0.2} \mathrm{RuO}_{2.1}$.

Figure 4 . The reciprocal of the susceptibility normalized to the susceptibility at $300 \mathrm{~K}$ $\left(\chi_{(300)} / \chi\right)$ as a function of temperature for layered (a) $\mathrm{K}_{0.2} \mathrm{RuO}_{2.1}$, (b) $\mathrm{H}_{0.2} \mathrm{RuO}_{2.1}$, (c) $\left(\mathrm{C}_{2} \mathrm{H}_{5} \mathrm{NH}_{3}\right)_{0.2} \mathrm{RuO}_{2.1}$, and (d) $\left(\left(\mathrm{C}_{4} \mathrm{H}_{9}\right)_{4} \mathrm{~N}\right)_{0.2} \mathrm{RuO}_{2.1}$. 


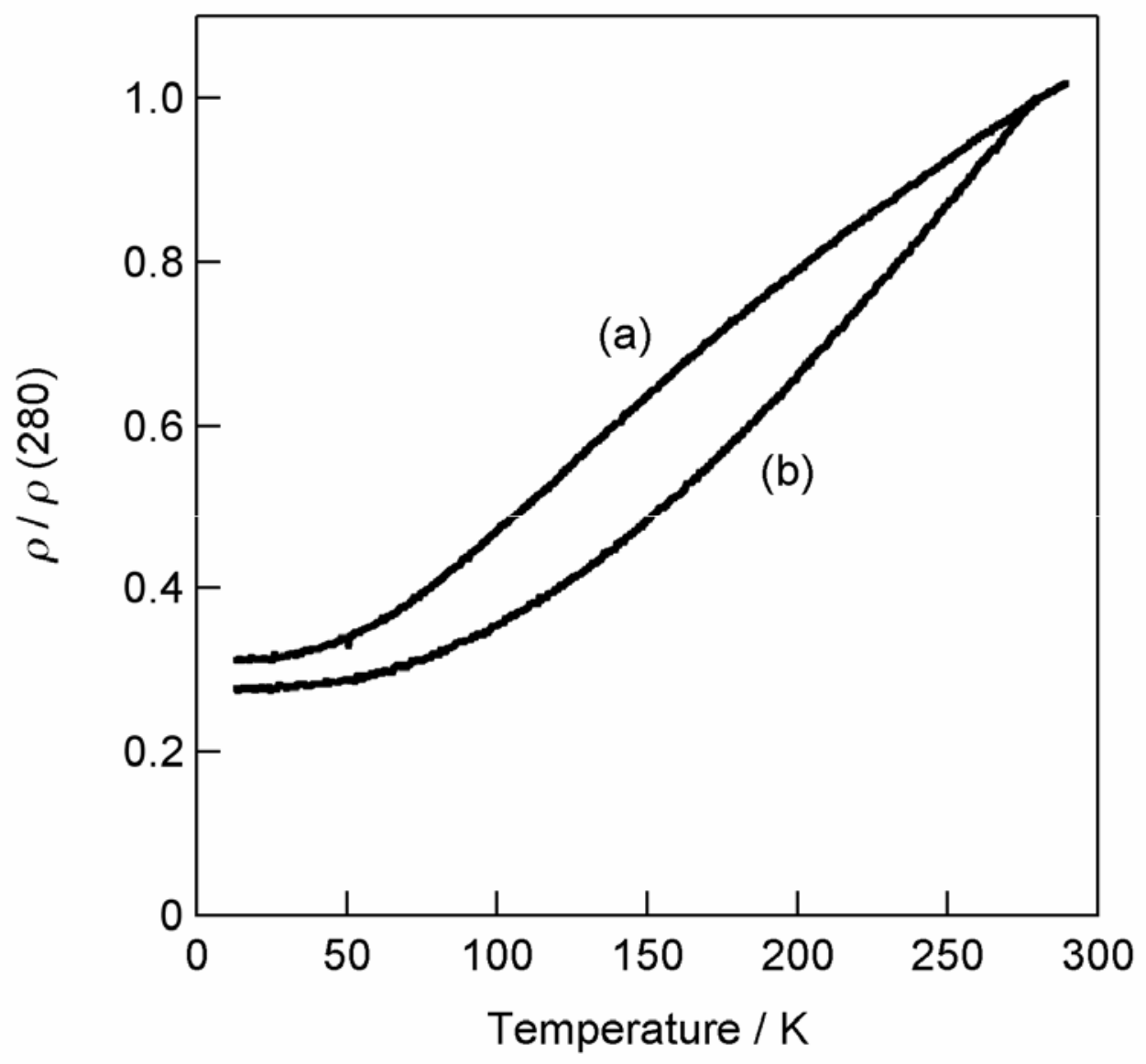

Figure 1 . The normalized resistivity as a function of the temperature for sintered pellets of (a) layered $\mathrm{K}_{0.2} \mathrm{RuO}_{2.1}$ and (b) rutile-type $\mathrm{RuO}_{2}$. 


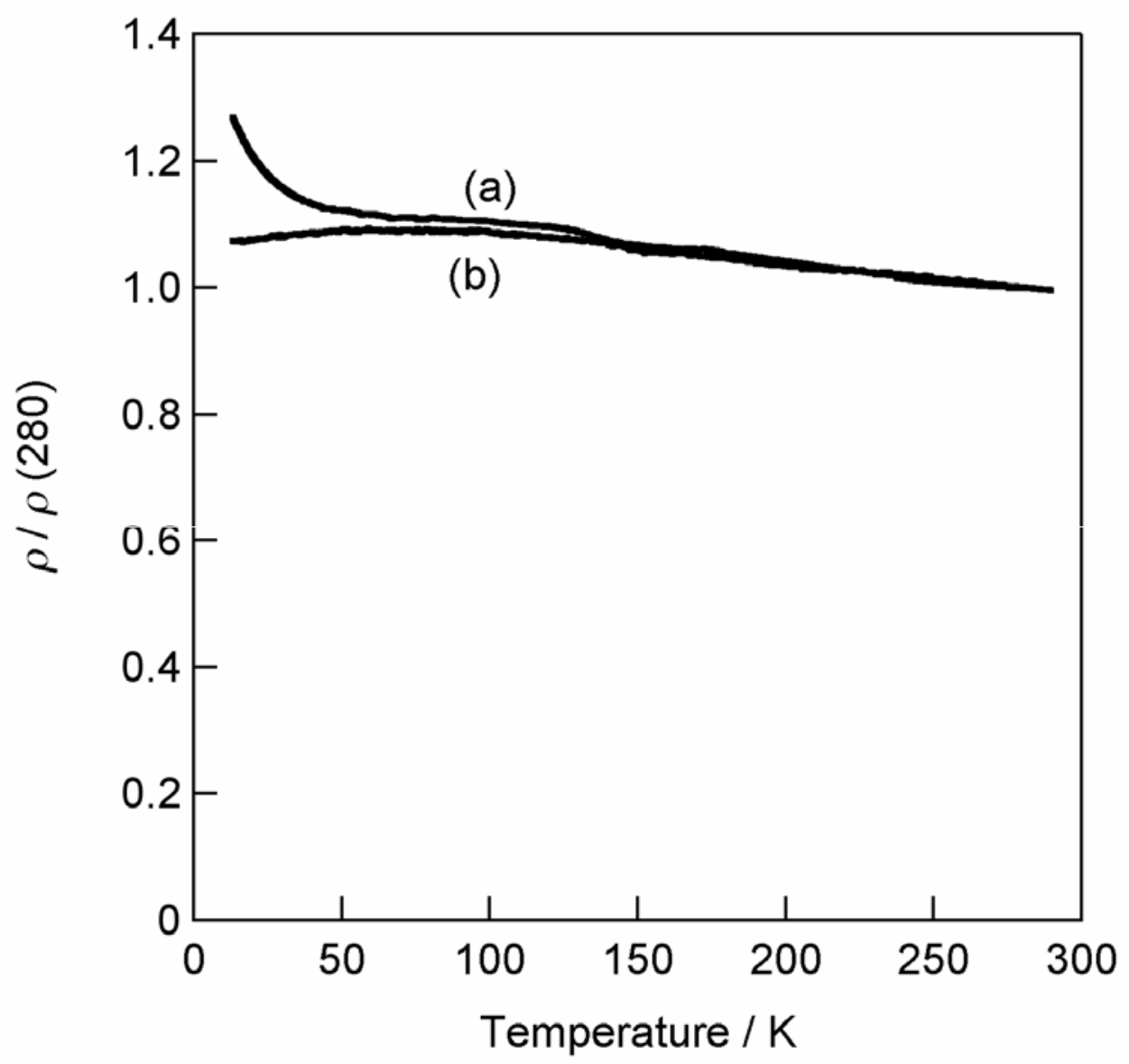

Figure 2. The normalized resistivity as a function of the temperature for non-sintered pellets of (a) layered $\mathrm{H}_{0.2} \mathrm{RuO}_{2.1}$ and (b) $\mathrm{RuO}_{2} \cdot n \mathrm{H}_{2} \mathrm{O}$. 


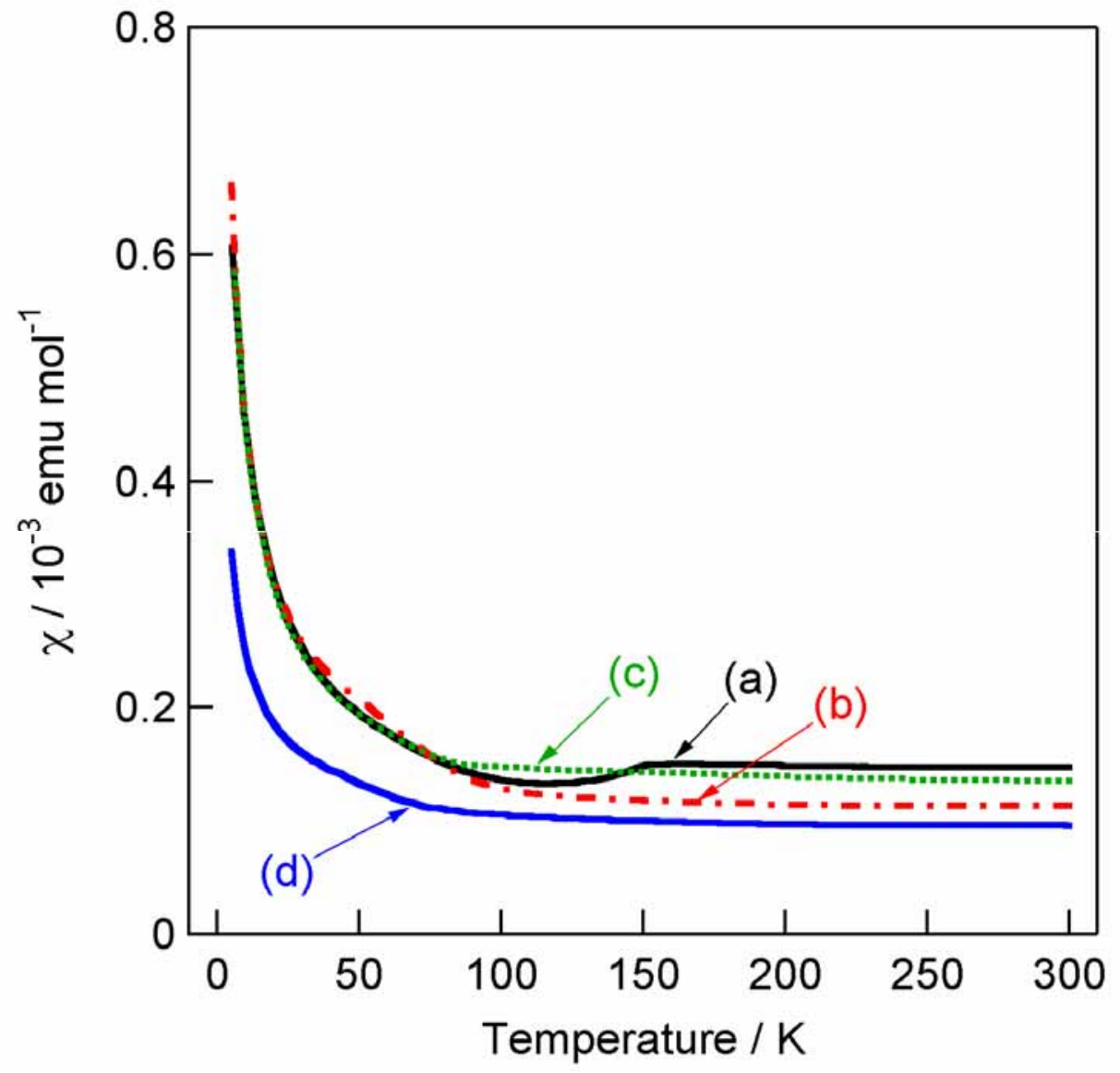

Figure 3. The magnetic susceptibility for layered (a) $\mathrm{K}_{0.2} \mathrm{RuO}_{2.1}$, (b) $\mathrm{H}_{0.2} \mathrm{RuO}_{2.1}$, (c) $\left(\mathrm{C}_{2} \mathrm{H}_{5} \mathrm{NH}_{3}\right)_{0.2} \mathrm{RuO}_{2.1}$, and (d) $\left(\left(\mathrm{C}_{4} \mathrm{H}_{9}\right)_{4} \mathrm{~N}\right)_{0.2} \mathrm{RuO}_{2.1}$. 


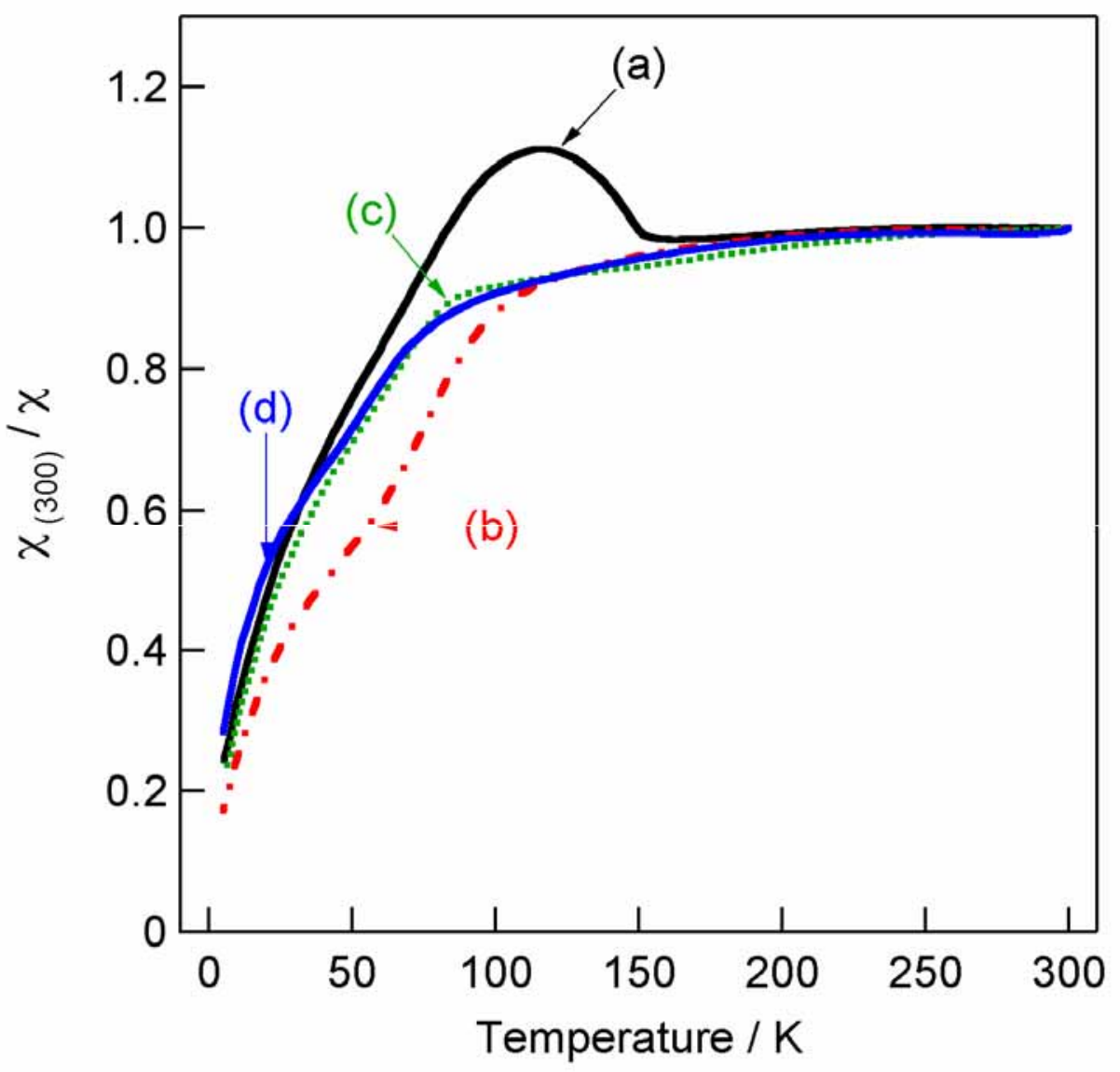

Figure 4. The reciprocal of the susceptibility normalized to the susceptibility at $300 \mathrm{~K}$ $\left(\chi_{(300)} / \chi\right)$ as a function of temperature for layered (a) $\mathrm{K}_{0.2} \mathrm{RuO}_{2.1}$, (b) $\mathrm{H}_{0.2} \mathrm{RuO}_{2.1}$, (c) $\left(\mathrm{C}_{2} \mathrm{H}_{5} \mathrm{NH}_{3}\right)_{0.2} \mathrm{RuO}_{2.1}$, and (d) $\left(\left(\mathrm{C}_{4} \mathrm{H}_{9}\right)_{4} \mathrm{~N}\right)_{0.2} \mathrm{RuO}_{2.1}$. 